\title{
A STUDY ON THE MYCOLOGICAL PROFILE OF ONYCHOMYCOSIS
}

Saroj Golia, Vivek Hittinahalli, Vasudha C. L, Sangeetha K. T, Madan Mohan, Clarify Syrti

1. Professor \& Head, Department of Microbiology, Dr. B. R. Ambedkar Medical College.

2. Associate Professor, Department of Microbiology, Dr. B. R. Ambedkar Medical College.

3. Post Graduates Student, Department of Microbiology, Dr. B. R. Ambedkar Medical College.

4. Post Graduates Student, Department of Microbiology, Dr. B. R. Ambedkar Medical College.

5. Associate Professor, Department of Microbiology, Dr. B. R. Ambedkar Medical College.

6. Post Graduates Student, Department of Microbiology, Dr. B. R. Ambedkar Medical College.

\section{CORRESPONDING ADDRESS:}

Dr. Vivek Hittinahalli,

NABH Assessor

Associate Professor,

Dr B.R Ambedkar Medical College

E-Mail: vivekhitt@yahoo.com,

Phone: 00917760984581.

ABSTRACT: BACKGROUND: Onychomycosis refers to fungal infection of nails with various etiological agents, involving dermatophytes, yeasts and moulds. It constitutes an important health problem because of its rising prevalence and under-diagnosis especially in developing countries. AIMS: To analyse the mycological and cultural characteristics of onychomycosis with respect to the various etiological agents. SETTINGS AND DESIGN: Nail samples collected from patients attending the dermatology clinic of Dr B.R Ambedkar medical college were processed in the microbiology department of $\mathrm{Dr}$ B.R Ambedkar medical college. MATERIALS AND METHODS: Nail clippings and subungual scrapings of patients with onychomycosis were subjected to $\mathrm{KOH}$ preparation. Culture was done on Sabouraud's dextrose agar medium and Sabouraud's dextrose agar with 5\% chloramphenicol and cycloheximide. Species identification was done by colony characteristics, pigment production, slide culture and LPCB stain. RESULTS: Out of 98 cases, 73 showed the growth of fungus, amounting to $74.50 \%$ positivity. Among those 73 cases, the infective fungal agents predominantly were dermatophytes (54.80\%), and the rest were due to yeasts $(23.30 \%)$ and moulds $22 \%)$. Among the different species, Trichophyton rubrum (43.84\% ) accounted for the majority of dermatophytes; candida albicans $(16.44 \%)$ was the predominant yeast; and aspergillus niger $(16.44 \%)$ the commonest mould. The age group most commonly affected was 16-30yrs and males were commonly affected in our study. CONCLUSION: The present study highlights the need for microbiological confirmation in case of onychomycosis for appropriate management of onychomycosis cases and further epidemiological study.

KEY WORDS: Onychomycosis, Etiological agents, Dermatophytes, Trichophyton rubrum.

INTRODUCTION: The term onychomycosis is derived from the Greek word "onyx", a nail and "mykes" a fungus. ${ }^{1}$ "Onychomycosis" traditionally referred to as nondermatophytic infection of nail is now used as a general term to denote any fungal nail infection. ${ }^{2}$ It is defined as the fungal infection of nails caused by dermatophytes, yeasts and nondermatophyte moulds. It is one of the commonest nail disorders and accounts for upto $30 \%$ of all superficial fungal infections. ${ }^{3}$ This 
may occur as a primary event or a secondary infection of a previously diseased or traumatized nail.4

Recently there has been a worldwide increase in the incidence of onychomycosis with social, cultural and economical factors contributing to it. ${ }^{3}$ In developing countries, higher priorities in socioeconomic concerns and health issues for other diseases, have resulted in low awareness of onychomycosis. Though there is a clearly diseased appearance associated with this condition, it is often regarded as merely a cosmetic problem of relatively minor importance. ${ }^{1}$ Several factors implicated to the increase in disease are reduced peripheral circulation, diabetes, nail trauma and improper nail hygiene. ${ }^{5}$ Although not life threatening, onychomycosis may have significant clinical consequences such as secondary bacterial infection, chronicity, therapeutic difficulties and disfigurement in addition to serving as reservoir of infection. ${ }^{2}$ Common clinical features include discoloration of the nail plate, hyperkeratosis and brittle nails. ${ }^{6}$

This infection can be caused by dermatophytes, yeasts and nondermatophyte moulds. ${ }^{7}$ Certain skin conditions such as psoriasis, lichen planus, onychogryphosis and nail trauma can mimic onychomycosis. ${ }^{6}$ Hence laboratory investigations are needed to differentiate accurately between fungal infections and the above mentioned skin diseases.

In India relatively less work has been done on onychomycosis as compared to western countries. The evolving role of nondermatophytic moulds has added a new dimension to the clinical patterns of onychomycosis.

The present study was conducted to study the morphological patterns and to analyse the mycological and cultural characteristics of onychomycosis with respect to various etiological agents in view of the paucity of literature on onychomycosis from this part of the country.

MATERIALS AND METHODS: This was a prospective study carried out on all clinically suspected cases of onychomycosis presenting to the dermatology clinic of Dr B.R. Ambedkar Medical College, Bangalore over a period of 6 months (may 2012 to October 2012) were included in the study.

SPECIMEN COLLECTION: Specimen collected were:- Nail and subungual scrapings from suspected cases of Onychomycosis.

First the affected area was cleaned with $70 \%$ ethanol. Nail and subungual scrapingswere collected with a surgical blade and sent in sterile petri dishes to microbiology department. The samples were subjected to microscopic examination and culture. The nail samples were subjected to $20 \%$ potassium hydroxide $(\mathrm{KOH})$ examination $^{14}$ and the softened nail materials were examined under both low and high power of the microscope for the presence of fungal elements. The details regarding the hyphae, spores, budding cells and pseudo-hyphae were noted.

For culture all the samples were inoculated on:

(1) Sabouraud's dextrose agar

(2) Sabouraud's dextrose agar with $5 \%$ chloramphenicol and cycloheximide. Cultures were incubated at $25^{\circ} \mathrm{C}$ and $37^{\circ} \mathrm{C}$ for 6 weeks and examined daily for the growth. The identification of isolate from the growth was done on the basis of colony morphology and wet mount microscopy with lactophenol cotton blue stain and slide culture technique. The morphological characteristics of the colony such as colour of the colony, type of the growth 
whether fluffy, cottony or creamy and the pigment produced on reverse were carefully observed and noted. For wet mount the material was taken from the growth with a wire loop and placed in a drop of lactophenol cotton blue stain on the glass slide. The material was evenly teased with a teasing needle known as 'spud needle' and observed under both low and high power of microscope. The details about the hyphae, the type of conidia and their arrangement were observed and recorded. ${ }^{8}$ The dermatophytes and nondermatophytic moulds were confirmed by slide culture technique.

The following criteria were taken into consideration to consider nondermatophyte mould as pathogen:

1) A direct positive mycological examination presenting large and irregular septate hyphae

2) Growth of the same agent in pure culture in at least three tubes of SDA

3) No development of dermatophytes

4) Repetition of these criteria after an interval of 2 weeks.$^{8}$

The candida spp were identified by gram stain, germ tube test, growth at $42^{\circ} \mathrm{c}$ and chrom agar.

RESULTS: A total of 98 patients (57 males and 41 females) were examined during the study period. Amongst these 98 patients with clinical manifestation in the nails, 58 ( $59.18 \%)$ had onychomycosis by direct microscopy and fungal cultures were positive in 73 specimens (74.45\%).(table-3, chart-2).

The age of the patients varied from 6-75 years, majority (40.82\%) i.e 40 out of 98 patients were between 16-30 years of age and the ratio of male to female was approximately 1.4:1 (table-1 \& 2, chart-1)

The most frequently isolated fungus was dermatophytes in $40(54.80 \%)$ patients followed by yeasts in 17 (23.30\%) patients, Aspergillus spp in 12 (16.44\%) patients and Fusarium in $4(5.50 \%)$ patients. Of the 40dermatophytes isolated, Trichophyton rubrum was the most commonest, (figure-1 \& 2) accounting for 32 (43.84\%) cases of onychomycosis, followed by Trichophyton mentagrophytes $6(8.22 \%)$ cases and Trichophyton tonsurans 2 $(2.74 \%)$ cases. Candida albicans was the predominant yeast $12(16.44 \%)$ cases followed by Candida dubliniensis 5 (6.84\%) cases. Aspergillus niger was the commonest nondermatophytic mould in 12 (16.44\%) cases, followed by Fusarium spp in 4 (5.50\%) cases (table-4, chart-3) The above data were analysed using Microsoft excel.

DISCUSSION: The importance of onychomycosis is often underestimated. Far more than being a simple cosmetic problem, infected nails serve as a chronic reservoir of infection which can give rise to repeated mycotic infections of the skin.

Onychomycosis occurs worldwide. Onychomycosis appears to be a variable entity presenting in different forms in different part of the world with every country and every region of the same country having its own characteristics of presentation.

In our study the isolation rate of onychomycosis was found to be $74.50 \%$. Even studies from Sikkim and Turkey showed a higher isolation rate of $82.35 \%$ and $86.9 \%$ respectively (Martinez et al.,2009; ${ }^{8}$ Kaur et al.,2007; ${ }^{9}$

The commonest age group affected in our study was 16-30 yrs(40, 40.82\%) followed by $31-45 y r s(24,24.49 \%)$. This was in concordance with studies done by Jesudanam et al.,200210 
and Reddy et al.,1982. ${ }^{11}$ Higher isolation rate was noted among males (75.43\%) than females, which was in concordance with most of the studies( Malik et al.,2009; ${ }^{6}$,Yehia et al.,2010;12 Ahuja et al.,2011; $)^{2}$

The most common isolate obtained in our study was Trichophyton rubrum (43.84\%). It has been reported as most prevalent pathogen in onychomycosis by many studies (Ahmad et al.,2010; ${ }^{3}$ Kaur et al.,2012;).13 The high rate of isolation of T.rubrum can be explained on the basis that it has greater capacity to infect the nails because it can easily colonise on hard keratin. Other dermatophytes isolated were T. mentagrophytes $(8.22 \%)$ and T.tonsurans $(2.74 \%)$.The second most common isolate in our study was candida spp (22.30\%) in which Candida albicans was most frequently reported (16.44\%).The third most common isolate in our study was Aspergillus niger (16.44\%). The other nondermatophytic mould isolated was Fusariumspp (5.50\%).

In our study dermatophytes were the most common group followed by yeasts and then nondermatophyte moulds in the etiology of onychomycosis. Trichophyton rubrum was the most common isolate, followed by Candida spp and then Aspergillus niger.

Onychomycosis can no longer be considered a simple cosmetic problem confined to the nails. Even with apparently optimal diagnosis patients are not cured by current therapies owing to misidentification of the pathogen, presence of a second disorder, characteristics of the nails, presence of a high fungal inoculum and/or drug resistant microorganisms, compromised immune system of the host, diabetes mellitus or peripheral vascular disease.

The single area most deserving of our attention in the near future is that of improving diagnostic methods. Diagnostic methodology and fungal susceptibility testing lag behind therapeutic advances. We should turn our attention to these problems.

\section{REFERENCES:}

1. Kaur R, Kashyap B, Bhalla P. Onychomycosis - Epidemiology, diagnosis and management. Indian Journal Of Medical Microbiology 2008;26(2):108-16.

2. Sanjiv A, Shalini M, Charoo H. Etiological agents of onychomycosis from a tertiary care hospital in Central Delhi, India. Indian Journal Of Fundamental And Applied Life Sciences 2011;vol 1(2):11-14.

3. Ahmad M, Gupta S, Gupte S. A clinic-mycological study of onychomycosis. Egyptian Dermatology Online Journal 2010;6(1):4.

4. Gupta M, Sharma NL, Kanga AK, Mahajan VK andTegta GR. Onychomycosis: Clinicomycologicalstudy of 130 patients from Himachal Pradesh, India.Indian Journal of Dermatology, Venereology\&Leprology 2007;73:389-392.

5. Veer P, Pathwardhan NS and Damle AS. Study of onychomycosis: Prevailing fungi and pattern of infection. Indian Journal of Medical Microbiology 2007; 25:53-56.

6. Malik NA, Raza N and Nasiruddin. Nondermatophyte moulds and yeasts as causative agents in onychomycosis. Journal of Pakistan Association of Dermatologist 2009;19: 7478.

7. Yenisehirli G, BulutY,Sezer E and Gunday E. Onychomycosis Infections in the middle black sea region, Turkey. International Journal of Dermatology 2009;48: 956-959.

8. Martinez PG, Nunes FG, Tomimori-Yamashita J, Urrutia M, Zarror L, Silva V and Fishman O. Mycopathologia 2009;168:111-116. 
9. Kaur R, Kashyap B and Bhalla P. A five- year survey of onychomycosis in NewDelhi,India: Epiemiology and laboratory aspects. Indian Journal of Dermatology 2007;52:39-42.

10. Jesudanam MT, Rao GR, Lakshmi DJ and Kumari GR. Onychomycosis. A significant medical problem. Indian Journal of Dermatology, Venereology \&Leprology 2002; 68: 326-329

11. Reddy BSN, Ramesh V and Singh R. Clinicomycological study of onychomycosis. Indian Journal of Dermatology, Venereology \&Leprology 1982;48:145-150.

12. Yehia MA, El-Ammawi TS, Al-Mazidi KM, Abu El- Ela MA and Al-Ajmi HS. The Spectrum of fungal infections with a special reference of dermatophytoses in the capital area of Kuwait during2000-2005:A retrospective analysis. Mycopathologia 2010; 169: 241-246.

13. Kaur T, Puri N. Onychomycosis- A clinical and mycological study of 75 cases. Our Dermatol Online 2012;3(3):172-177.

14. Flores J.M, Castillo V.B, Franco F.C, Huata A.B- Superficial fungal infections: clinical and epidemiological study in adolescents from marginal districts of Lima and Callao, Peru. J Infect DevCtries 2009; 3(4):313-317.

Table 1

Age distribution in patients of onychomycosis

\begin{tabular}{|l|c|c|c|c|}
\hline \multirow{2}{*}{ Age group (in years) } & \multicolumn{2}{|l|}{ No of cases } & \multirow{2}{*}{ Total } & $\%$ age \\
\cline { 2 - 3 } & male & female & & \\
\hline $05-15$ & 09 & 06 & 15 & $15.31 \%$ \\
\hline $16-30$ & 22 & 18 & 40 & $40.82 \%$ \\
\hline $31-45$ & 13 & 11 & 24 & $24.49 \%$ \\
\hline $46-60$ & 05 & 08 & 13 & $13.26 \%$ \\
\hline $61-75$ & 04 & 02 & 06 & $06.12 \%$ \\
\hline
\end{tabular}

Table 2

Sex distribution in patients of onychomycosis

\section{Table 3}

\begin{tabular}{|l|l|l|}
\hline SEX & NO OF CASES & \% AGE \\
\hline Male & 57 & $58.16 \%$ \\
\hline Female & 41 & $41.84 \%$ \\
\hline Total & 98 & $100 \%$ \\
\hline
\end{tabular}

Direct microscopy (KOH preparation) vsfungal culture in the diagnosis of onychomycosis $(n=98)$

\begin{tabular}{|l|c|c|c|}
\hline Diagnostic tests & KOH positive & KOH negative & Total \\
\hline $\begin{array}{l}\text { Fungal culture } \\
\text { positive }\end{array}$ & 47 & 26 & 73 \\
\hline $\begin{array}{l}\text { Fungal culture } \\
\text { negative }\end{array}$ & 11 & 14 & 25 \\
\hline Total & 58 & 40 & 98 \\
\hline
\end{tabular}


Table 4 The different categories of fungi isolated from onychomycosis cases with their comparative percentage of occurrence

\begin{tabular}{|l|c|c|}
\hline \multicolumn{1}{|c|}{ Type of fungi } & No of positive cases ( n= 73) & Percentage \\
\hline Dermatophytes : & & \\
\hline T.rubrum & 32 & $43.84 \%$ \\
\hline T.mentagrophytes & 06 & $08.22 \%$ \\
\hline T.tonsurans & 02 & $02.74 \%$ \\
\hline Yeasts: & 12 & $16.44 \%$ \\
\hline Candida albicans & 05 & $06.84 \%$ \\
\hline Candida dubliniensis & 12 & $16.44 \%$ \\
\hline Nondermatophytic moulds: & 04 & $05.50 \%$ \\
\hline A.niger & 73 & $100 \%$ \\
\hline Fusariumspp & & \\
\hline Total : & & \\
\hline
\end{tabular}

Table -5Morphological and microscopic patterns of various isolates

\begin{tabular}{|l|l|l|}
\hline Fungal isolates & Colony morphology & Microscopic identification \\
\hline Dermatophytes & $\begin{array}{l}\text { White downy colonies with } \\
\text { rugal fold, reverse is wine red } \\
\text { colour. }\end{array}$ & $\begin{array}{l}\text { Tear drop shaped microconidia } \\
\text { with few pencil shaped } \\
\text { macroconidia }\end{array}$ \\
\hline T .rubrum & $\begin{array}{l}\text { White granular and fluffy } \\
\text { colonies, reverse is buff to } \\
\text { reddish brown. }\end{array}$ & $\begin{array}{l}\text { Grape like clusters of round } \\
\text { microconidia with thin-walled, } \\
\text { club shaped, } \\
\text { multiseptatemacroconidia. }\end{array}$ \\
\hline T .tonsurans & $\begin{array}{l}\text { White, wrinkled with heaped } \\
\text { center, reverse yellow to tan. }\end{array}$ & $\begin{array}{l}\text { Club shaped microconidia with flat } \\
\text { bottoms, few balloon shaped } \\
\text { macroconidia. }\end{array}$ \\
\hline Yeasts & Cream, smooth, pasty colonies & Grams stain \\
\hline Candida albicans & Cream, smooth, pasty colonies & Gram positive budding yeast cells. \\
\hline Candida dubliniensis & LPCB stain \\
\hline Nondermatophytic moulds: & $\begin{array}{l}\text { Wooly brown to black } \\
\text { colonies, reverse white to } \\
\text { yellow. }\end{array}$ & $\begin{array}{l}\text { Conidiophore of variable length, } \\
\text { biseriatephialides cover entire } \\
\text { vesicle forming radiate head, } \\
\text { conidia are black. }\end{array}$ \\
\hline A.niger & $\begin{array}{l}\text { Fluffy to cottony colonies with } \\
\text { orange pigment. }\end{array}$ & $\begin{array}{l}\text { Multicelled sickle shaped } \\
\text { macroconidia }\end{array}$ \\
\hline Fusariumspp & &
\end{tabular}




\section{Chart -1}

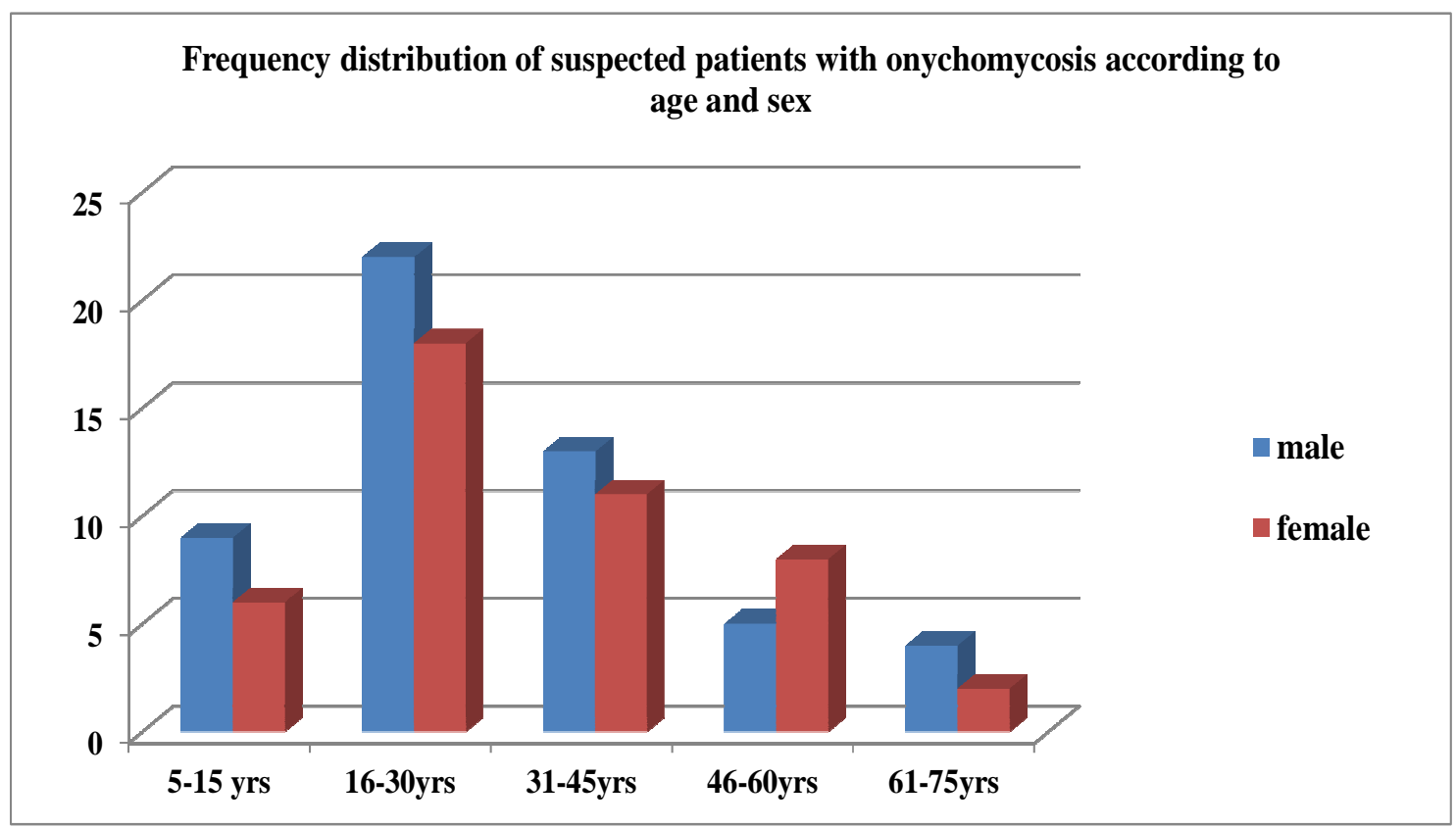

Chart -2

Direct microscopy vs fungal culture

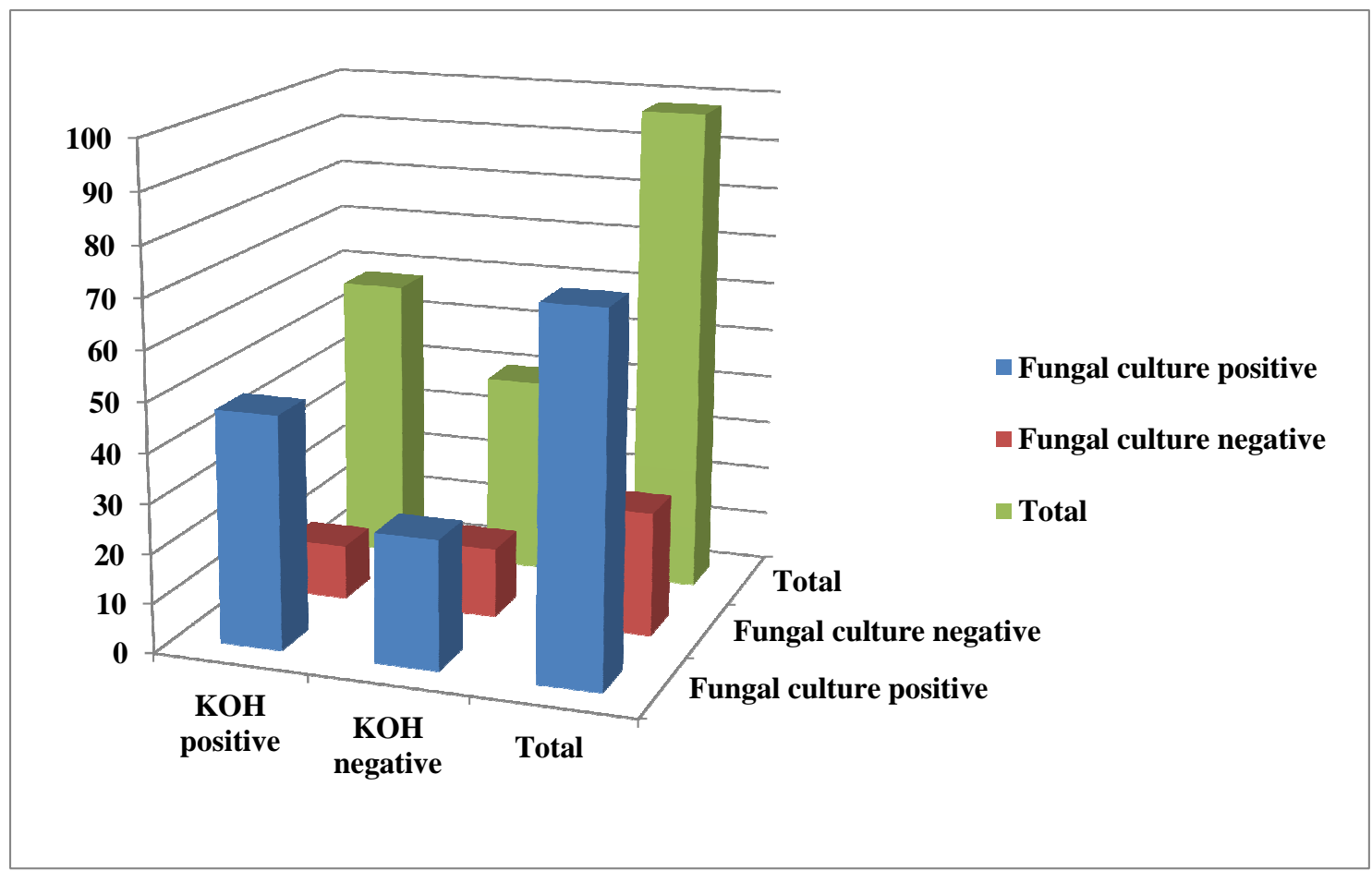




\section{Chart-3}
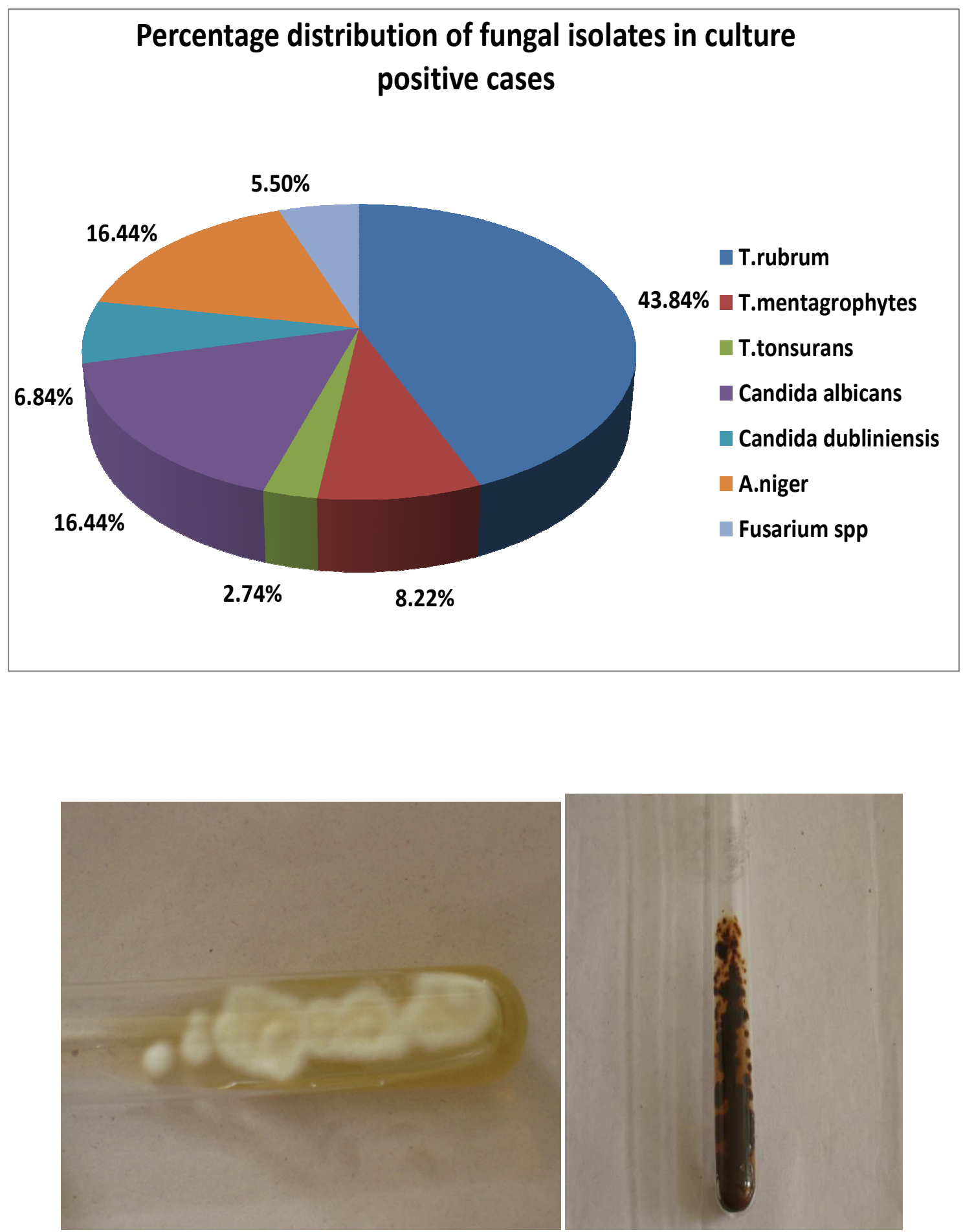

Colony morphology of Trichophytonrubrum 


\section{ORIGINAL ARTICLE}

Figure -2

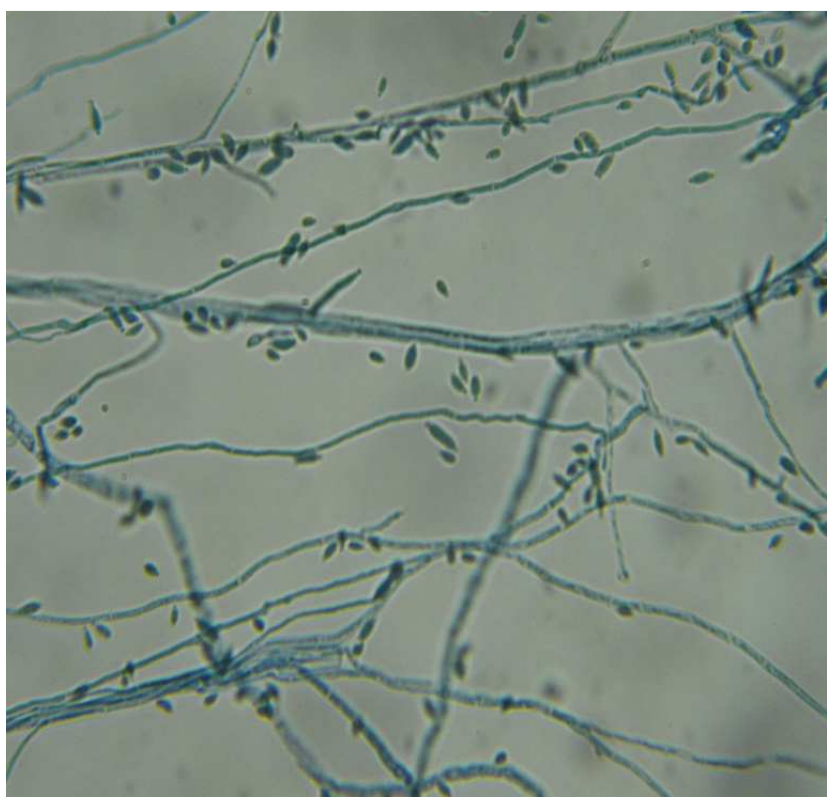

Microscopic morphology in lactophenol cotton blue stain -Trichophytonrubrum 